\title{
Regiões metropolitanas, a experiência brasileira e suas perspectivas
}

\section{O Brasil dos anos 80}

Os resultados preliminares do último censo apresentaram a face marcante do Brasil dos anos 80: um país urbano. Os dados revelaram que: a) $67 \%$ da população brasileira, cerca de 80 milhões de pessoas, vivem nas cidades; b) $29 \%$ dessa população, ou seja, aproximadamente 36 milhões de habitantes, residem nas nove regiões metropolitanas; c) cerca de trezentos, dos 4 mil municípios brasileiros, concentram metade da população nacional.

Este quadro significa que, do ponto de vista territorial, o país vem sofrendo um processo de urbanização acelerada e de concentração demográfica, com tendência a agravar os desequilíbrios regionais e a provocar distorções no crescimento das cidades. Significa, também, que está ampliada a responsabilidade social do administrador público, no sentido de orientar os investimentos de forma a promover a ocupação mais equilibrada do nosso território, através do estabelecimento de um sistema de cidades que assegure melhor distribuição regional do desenvolvimento.

Para alcançar esses objetivos, é necessário intensificar o uso de mecanismo voltados para obter a atuação coordenada entre as três esferas de governo e ação articulada com o setor privado.

Torna-se indispensável dar continuidade, com firmeza, à estratégia de desconcentração urbana, de modo a consagrar um padrão de desenvolvimento que aproveite as potencialidades do país, como um todo, que limite os graus de poluição nos centros industriais mais avançados, que possibilite a prestação dos serviços públicos em níveis mais adequados e que contribua para reduzir a tensão psicossocial nas áreas urbanas.

Verifica-se a existência de resistentes bolsões de pobreza urbana, concentrados nos segmentos de baixa renda, isolados nas periferias das grandes cidades, somando mais de 1 milhão de pessoas em São Paulo e cerca de 400 mil favelados no Recife.

Parece indiscutivel afirmar que a origem dessa configuração urbana está na ausência de uma estrutura mais ampla de serviços e de geração de emprego no meio rural e nas cidades do interior do país, provocando as migrações.

Com efeito, ainda com base no censo de 80 , verifica-se que cerca de 8 milhões de domicílios, localizados nas cidades brasileiras de pequeno e médio porte, não dispõem de redes de abastecimento d'água; que, no mesmo universo, aproximadamente $2 / 3$ dos domicílios não contam com sistema de esgotamento; que 1.300 municípios, durante a década de 1970, perderam população. É oportuno ressaltar que, de acordo com pesquisas realizadas sobre migração, essa perda de população se deve à inexistência, no lugar de origem, de emprego, de oferta de escola e de serviço médico. 
A gestão metropolitana

A problemática urbana, no país, vem recebendo, desde 1973, tratamento sistemático, por parte do governo federal, através de processos modeladores da organização institucional e da ação programática.

Efetivamente, a partir de estudos realizados pelo IPEA, que subsidiaram a definição das nove atuais regiões metropolitanas - Belém, Fortaleza, Recife, Salvador, Belo Horizonte, Rio de Janeiro, São Pau10, Curitiba e Porto Alegre - , através das leis complementares n. 14 e n. 20, vêm sendo desenvolvidos esforços para identificar e equacionar as questões relacionadas com a administração metropolitana.

Essa legislação introduziu, entre outros, dois aspectos normativos básicos: primeiro, o de que, em respeito ao princípio da Federação, cabe ao governo dos estados a competência para gerir o planejamento metropolitano; segundo, o de que a gestão metropolitana se dá através da unificação e da prestação de serviços de interesse comum, nas áreas de planejamento integrado, saneamento básico, uso do solo, transportes e sistema viário, gás canalizado e aproveitamento de recursos hídricos e controle da poluição ambiental.

A institucionalização dessas nove regiões metropolitanas encontrou justificativa na realidade; em todas elas, a configuração física e as condições sócio-econômicas, hoje ou no futuro próximo, exigem a adoção de um esquema de ação metropolitana. O esforço voltado para promover a industrialização, nas três últimas décadas, contribuiu em grande parte para o surgimento dessas aglomerações. O censo de 80 registrou um incremento demográfico nas regiões metropolitanas, durante a década de 1970: de 4,39\% ao ano em Salvador; de $4,67 \%$ ao ano em Belo Horizonte; de $4,45 \%$ ao ano em São Paulo; e de até 5,80\% ao ano em Curitiba.

A velocidade com que se formam essas concentrações urbanas e o porte que hoje apresentam, torna indispensável a utilização da forma de gestão metropolitana, capaz de atender eficientemente a demanda por infra-estrutura e por serviços sociais básicos.

O estabelecimento das regiões metropolitanas, inseridas na competência dos governos estaduais, em sintonia com o espírito federativo, objetiva principalmente organizar, de forma conveniente, os serviços de caráter supramunicipal. Este é um dos mais relevantes aspectos da legislação metropolitana. Todavia, a execução das ações em nível metropolitano, na prática, não correspondeu, nesse particular, aos propósitos do legislador.
Com exceção da função de planejamento, que obteve avanços significativos em algumas regiões metropolitanas, através do envolvimento dos órgãos setoriais e das prefeituras, no caso das demais funções não ocorreu a unificação dos serviços de inte resse metropolitano.

Na verdade, nos últimos oito anos o acervo de experiência da administração metropolitana, no país, indica como característica dominante o esforço em busca da articulação de ações.

Verifica-se que a tarefa principal, a que se dedicaram os gestores metropolitanos, foi a de assegurar grau adequado de integração de iniciativas não só entre as esferas de governo-União, estados e municípios, mas também do ponto de vista intersetorial, procurando compatibilizar as ações sobre uma mesma área. Nesse caso, não se trata de sobrepor a variável espaço à ação setorial, mas de imaginar cenários alternativos para ocupação do solo urbano, de maneira socialmente desejável.

O administrador metropolitano reconheceu que, na impossibilidade de adotar um esquema mais formalizado de trabalho, uma das maneiras eficazes de consolidar a região metropolitana, era basear sua atuação no âmbito do entendimento político, da solidariedade administrativa, de modo a gerar condições de estabilidade ao funcionamento do sistema metropolitano.

De fato, deixando de haver, como pretendera a lei complementar n: 14, a unificação dos serviços de interesse comum, a função metropolitana por excelência passou a ser a integração de ações, demonstrada na tentativa do órgão metropolitano de exercitar a coordenação de programas, junto às agências setoriais do governo do estado, e de promover a articulação intergovernamental em relação às demais esferas de poder.

Esse esforço parece ser coerente não só quanto às condições de operação da administração, mas igualmente em relação ao contexto do federalismo.

A elaboração e implementação de planos de desenvolvimento devem-se basear, pelo menos, em dois pressupostos principais: a compatibilidade dos objetivos estabelecidos pelos órgãos que atuam nos diversos níveis de poder, e a harmonização das metas definidas pelos órgãos setoriais.

Trata-se de alcançar esperada convergência na execução das ações da União, estados e municípios, e garantir a necessária compatibilidade entre os programas de transporte, habitação, saneamento, indústria, lazer etc.

Essa tarefa é tanto mais exigida quando se atua no espaço das regiões metropolitanas, onde a densidade de população, a demanda de bens e serviços 
e a localização de equipamentos requerem crescente racionalidade na aplicação dos investimentos. Nesse sentido, a edição do decreto n: 85.916/81 e a resolução no $13 / 81$ do Conselho Nacional de Desenvolvimento Urbano constituem elementos fundamentais para orientar esse procedimento. Trata-se de um conjunto de normas que determinam diretrizes sobre as atividades da administração pública nas regiões metropolitanas, com o objetivo, entre outros, de propiciar a compatibilização entre o planejamento e a programação financeira federal e o programa de investimentos das regiões metropolitanas.

O cumprimento desse decreto possibilita a elaboração mais segura dos planos metropolitanos de desenvolvimento em decorrência do conhecimento e da discussão das diretrizes contidas nos programas federais. Assegura, igualmente, a obtenção, em 1983, de um quadro programático a ser considerado pelos novos administradores eleitos em 1982, contribuindo para a existência do almejado grau de continuidade administrativa. Garante, também, a crescente democratização das políticas públicas, através de debate e do ajustamento entre os programas federais e as prioridades previstas nos planos metropolitanos, cuja elaboração deve resultar do entendimento do gestor metropolitano com os municípios integrantes da região metropolitana.

Configura-se, assim, o encadeamento de propósitos e iniciativas, que vão se adequando desde a base municipal até o nível federal, através de um trabalho de adensamento gradual e de ajustes sucessivos.

De outra parte, esse esforço pretende reunir um conjunto amplo de informações econômicas, sociais e urbanísticas, contidas nos planos metropolitanos, para permitir a construção de um quadro referencial capaz de subsidiar a atualização, oportunamente, das diretrizes e objetivos da política nacional de desenvolvimento urbano.

Com base, entre outras, nas proposições definidas pelos planos metropolitanos, será possível reorientar a política de desenvolvimento urbano, de modo a melhor conectá-la com as vocacões e as necessidades das regiões e dos estados. É, portanto, uma via ampla de entendimento entre os níveis de governo e os órgãos setoriais, possibilitando a expressão das prioridades estaduais e municipais. Essa orientação contribui para incorporar progressivamente um novo estilo de planejamento, mais aberto e participativo. Procura envolver a sociedade não apenas como beneficiária, mas também como sujeito da ação do governo e busca sintonia entre o que é desejável pela comunidade e o que é viável realizar pela administração pública.

Amplia-se a escala social do planejamento, aumentando suas fontes de formulação e elevando sua capacidade crítica. A prática desse estilo de planejamento é especialmente recomendável nas cidades, onde a convivência urbana deve aproximar solidariamente as pessoas e onde cada um deve ser co-partícipe da gestão social.

\section{Por uma política social urbana}

Os investimentos realizados pelo setor público nas regiões metropolitanas, ao longo da última década, estiveram quase sempre voltados para financiar a construção da infra-estrutura física, sobretudo do sistema viário.

A aplicação de recursos nos setores sociais de educação, saúde, abastecimento, habitação e saneamento se fez de forma residual e não correspondente à ampliação da demanda por esses serviços verificada nos aglomerados metropolitanos.

No caso de habitação, ressalte-se o reconhecido esforço promovido pelo BNH, a partir de 1980 , com a prioridade conferida aos programas habitacionais de interesse social e, em especial, com a criação do PROMORAR, destinado a promover a recuperação de favelas e a financiar a aquisição da casa própria para as pessoas com rendimento entre $1 \mathrm{e}$ 3 salários mínimos.

A elevada concentração demográfica ocorrida nas regiões metropolitanas, sem a desejada contrapartida de oferta dos serviços sociais básicos, configura uma tendência de agravamento das condições de vida para as populações carentes.

É também reconhecida a situação de desigualdade na distribuição de renda, que caracteriza, por exemplo, a região metropolitana do Recife, onde cerca de $80 \%$ da população economicamente ativa ganham entre 1 e 2,5 salários mínimos.

Por essas razões, é imperativa e oportuna a formulação de uma política social urbana, que coordene ações, articule níveis e setores do governo, concentre recursos e seja coerente com a natureza e a dimensão dos problemas que, hoje, afetam grande parte das populações que residem nas regiões metropolitanas.

Essa iniciativa é igualmente compatível com um novo estilo de planejamento, que busca ser mais flexível e descentralizado, na prática, e mais orientado para o atendimento das carências sociais, no conteúdo.

Os indicadores relacionados com a composição e o padrão sócio-econômico dessas populações sugerem, de modo claro, as linhas que devem compor a política social urbana. Com efeito, o objetivo da ação deve ser a periferia urbana e sua clientela preferencial - a população de menor renda. O per- 
fil e o grau de suas necessidades, a sua falta de integração ao sistema produtivo, a exasperação política a que está exposta, e o conteúdo ético da ação do administrador público, indicam ser indispensável selecionar a população pobre como objeto e sujeito da atuação governamental.

A ação do governo, voltada prioritariamente para promover a integração social da população de menor renda, poderia envolver o fortalecimento e a conjugação dos seguintes componentes: a) emprego e renda, objetivando realizar programas intensivos de mão-de-obra, capazes de ampliar as oportunidades de emprego, inclusive no setor informal urbano; b) habitação e saneamento, visando a elevar a oferta de casa própria, garantir a recuperação de favelas, inclusive com a regularização da posse da terra, e melhorar as condições de vida das populacõ̃es carentes; c) alimentação e nutrição, no sentido de assegurar a um número crescente de crianças do pré-escolar e do $1^{\circ}$ grau uma dieta que possibilite seu crescimento físico e desenvolvimento mental adequados; d) educação, com a finalidade de garantir a universalização do ensino de 1. grau e intensificar a realização de cursos profissionalizantes, ajustados ao perfil do mercado.

São diversos os programas realizados, atualmente, por entidades públicas dos vários níveis de governo, voltados para equacionar os problemas sociais. Todavia, as ações se ressentem da adoção de uma perspectiva programática, que as integre, fazendo com que a atuação coordenada do setor público produza os esperados resultados sociais e econômicos.

Acentue-se, igualmente, que a proximidade fisica existente entre o administrador estadual e municipal, de um lado, e os problemas básicos da comunidade, de outro, sugere que as ações de execução devem ser atribuídas ao estado e ao município.

Nesse sentido, a estratégia para operacionalizar, com eficácia, programas desse tipo, poderia comtemplar as seguintes linhas: a) coordenação de esforços e concentração de recursos, por parte do setor público como um todo, de modo a garantir ganhos administrativos e ampliar os efeitos sociais na implantação dos programas; b) descentralização das ações de execução, em favor dos estados e dos municípios, os quais, por deterem maior conhecimento sobre os problemas locais, dispõem de melhores condições para realizar os programas; c) seleção de áreas prioritárias, segundo critérios regionais, com a finalidade de ajustar a disponibilidade de recursos ao grau de carências sociais de determinados bolsões de pobreza urbana.

\section{Os novos parâmetros políticos}

O processo de aperfeicoamento das instituições democráticas - que o país vive - abrange a mudança do padrão de relacionamento entre o governo e a sociedade civil. Contempla graus mais elevados de participação social no âmbito das decisões governamentais. Incide, igualmente, na definição das políticas públicas relacionadas com a esfera econômica e social.

Suas conseqüências deverão repercurtir, também, no domínio da administração metropolitana, sobretudo em dois niveis: primeiramente, o da regulamentação da gestão urbana; em segundo lugar, o da organização da ação político-aministrativa.

No que diz respeito ao ordenamento legal da administração urbana, a recente iniciativa do Ministério do Interior, através do Conselho Nacional de Desenvolvimento Urbano (CNDU), de propor um novo estatuto jurídico que venha a apoiar a gestão urbana deve ser considerada no contexto das condições sociais e econômicas que caracterizam, atualmente, a sociedade brasileira, em especial nas cidades.

Com efeito, o Anteprojeto de Lei para o Desenvolvimento Urbano configura o propósito de articular, de forma orgânica, os instrumentos capazes de responder as demandas sociais que se antepõem, hoje, à competência do gestor público. É uma proposta que busca contribuir para que o processo de tranformação social se efetive de maneira pacífica e harmônica. O quadro de referência, que justifica a elaboração do mencionado anteprojeto, apresenta pelo menos quatro aspectos relevantes.

Em primeiro lugar, constata-se a defasagem entre as leis que regem o desenvolvimento urbano, sobretudo quanto ao planejamento das cidades e à operação dos serviços públicos, e a realidade de características reconhecidamente urbanas do país, atestada pelo censo de 1980.

Segundo, verifica-se a existência de resistentes níveis de pobreza urbana, concentrados nos segmentos de baixa renda, que habitam favelas da periferia. No caso de São Paulo, por exemplo, o número de favelados é aproximadamente igual ao total da população do Recife. Esses bolsões de pobreza carecem de praticamente todo tipo de serviço social básico.

Terceiro, observa-se o surgimento de graus crescentes de tensão psicossocial, nas regiões metropolitanas, em decorrência da insatisfação provocada pela ausência de oferta daqueles serviços de consumo coletivo, provocando o aumento da marginalidade e a incidência elevada de violência. 
Quarto aspecto, reconhece-se a necessidade de atualizar os mecanismos de ordenamento do espaço urbano, através da atuação mais eficaz do planejamento do uso do solo, de modo a obter-se crescente racionalidade na localização dos equipamentos e na distribuição de atividades e de população, e a evitar-se a depredação do patrimônio ecológico e cultural.

O controle do uso do solo é tanto mais indispensável quanto se identifica, no sítio urbano, o centro privilegiado de convivência, pois é na cidade onde não apenas devemos ficar próximos, mas onde podemos estar juntos, no esforço compartilhado de viver e construir.

De fato, o documento apresenta reconhecida dimensão social ao pretender que milhões de brasileiros tenham acesso aos serviços sociais básicos, gerados a partir da oferta ampliada de habitação, cujo déficit absoluto alcança mais de cinco milhões de unidades.

Envolve, além disso, a dimensão política da sociedade, ao contribuir, através da prática da distensão urbana, para assegurar níveis desejáveis de estabilidade do sistema social, beneficiando elevadas parcelas da população.

Concretiza, por sua vez, a dimensão econômica, na esfera de atuação dos agentes empresariais, porque cria condições para acelerar os investimentos reprodutivos na área urbana, estimulando a elaboração e execução de projetos habitacionais e de infra-estrutura, capazes de gerar novas fontes de renda pública e privada e de propiciar oportunidades adicionais de emprego.

O documento incorpora a dimensão urbanística das cidades, ao sugerir que seja introduzido, na legislação, um elenco coerente de medidas relacionadas com o seu planejamento, com o seu crescimento de forma equilibrada, com a atuação esperada do gestor público em relação aos problemas que afetam o sistema urbano, com a definição de normas que possibilitem melhor articulação intergovernamental.

Contempla ademais a dimensão ética do,governo, ao propor a execução de políticas públicas que expressem uma correspondência entre o que é socialmente necessário e o que é politicamente viável, estabelecendo almejada identificação de reiteradas aspirações sociais com as decisões da administração.

Na verdade, o Anteprojeto, coerente com a letra e o espírito da Constituição federal, pretende garantir a extensão quantitativa do direito de propriedade e assegurar, na prática, a sua função social.

O espaço urbano vem desempenhando papel crescente na modelação da vontade política da nação. É nas cidades, através de esforço consciente e solidário, que se projeta o perfil conteporâneo da sociedade brasileira. Torna-se oportuno conferir-lhes um estatuto que, sem deixar de ser singular, seja plural na sua destinação.

Quanto à organização da ação politico-administrativa, no âmbito das regiões metropolitanas, verifica-se a existência de um quadro novo, bem diferente daquele que prevalecia antes das eleições de novembro de 1982 .

A lei complementar $n$. 14, que estabeleceu as regiões metropolitanas e sua mecânica de funcionamento, definiu como entidades responsáveis pela gestão metropolitana os conselhos deliberativos e consultivo, ambos presididos pelo governador do estado, e um órgão de apoio técnico.

O Conselho Deliberativo é composto de um representante da prefeitura da capital, um representante das demais prefeituras da região metropolitana, e de três representantes de livre escolha do governador. O Conselho Consultivo conta com a participação dos prefeitos de todos os municipios da região metropolitana.

Os órgãos de apoio técnico às atividades desenvolvidas na região metropolitana assumiram diversas formas, na medida em que os governos dos estados pretenderam conferir-lhes maior ou menor capacidade de execução, maior ou menor grau de flexibilidade jurídica e operacional.

No caso do Recife, do Rio de Janeiro e de Porto Alegre, foram instituídas fundações; no caso de Fortaleza, de Belo Horizonte e de Curitiba, criaramse autarquias; no caso de São Paulo, foi organizada uma secretaria de estado, à qual se vincula uma empresa pública; no caso de Salvador, criou-se uma empresa pública.

Independente da forma jurídica assumida por essas entidades, o processo de planejamento e de execução das ações metropolitanas caracterizou-se sempre pela necessidade de garantir níveis razoáveis de articulação intergovernamental. Esta tarefa, como vimos anteriormente, tornou-se imprescindivel para compatibilizar os interesses e ajustar as programações definidas pelos órgãos da União, do estado e dos municípios, que intervêm no espaço metropolitano.

É oportuno ressaltar também que a condução das políticas metropolitanas realizou-se, com poucas e esparsas exceções, na base de decisões adotadas pelo governador do estado ou pela secretaria - à qual o órgão metropolitano está vinculado - e cumpridas por esse órgão, sem audiência dos conselhos deliberativo e consultivo. 
Essa prática, de certo modo, refletiu as condições políticas que condicionaram o processo decisório e a ação governamental, no passado recente, e que deverão orientar-se de acordo com outros padrões de relacionamento, processo que se iniciou com a posse das novas administrações, em março de 1983.

Até novembro passado, o contexto político do país apresentava um quadro bipartidário, com apenas um governo estadual de oposição ao governo da União. Com a realização das eleições, elevando o grau de participação da sociedade e possibilitando maior transparência dos anseios comunitários, a situação política foi alterada para incorporar não apenas diferentes representações partidárias, mas também novas qualificações sociais. Surgiu um novo cenário político-institucional, que modifica os parâmetros da ação administrativa e torna mais complexo o processo de gestão metropolitana.

Com efeito, o resultado das eleições determinou uma mudança no perfil político dos governos estaduais e, principalmente, no dos municípios que integram as regiões metropolitanas. Esse fato envolve uma série de configurações políticas de correspondência e não-correspondência político-partidária, nas regiões metropolitanas, sob o aspecto do relacionamento entre as três esferas de governo.

No caso das regiões metropolitanas de São Paulo e do Rio de Janeiro, por exemplo, há municípios cujos prefeitos são de oposição ao governo do estado, mas são do mesmo partido que apóia o go- verno federal. E há municípios cujos prefeitos são de oposição tanto em relação ao governo do estado quanto em face do governo da União.

Essa nova feição política, surgida no domínio das regiões metropolitanas, resultante das eleições, exige a ampliação do esforço de articulação intergovernamental, que já vinha sendo exercido pelo administrador metropolitano.

Impõe-se agora, diante da nova realidade, intensificar o diálogo político e alargar a faixa de negociação administrativa, entre o governo do estado e as prefeituras localizadas na região metropolitana, em favor da manutenção do sistema de planejamento e de execução das ações de interesse metropolitana e de seu crescente aperfeiçoamento.

É possível prever a possibilidade de enrijecimento da articulação entre os níveis de governo, tendo em vista a predominância de propósitos partidários.

É também correto supor que esse quadro evolua de maneira diferenciada, expressando a criatividade, o estilo e as peculiaridades locais.

Em qualquer das hipóteses, parece certo reconhecer que o clima político aberto à cooperação construtiva poderá contribuir não só para a prática do entendimento e da conciliação, mas também para obtenção de crescente coerência entre o que é socialmente desejável e o que é politicamente viável alcançar. 